\title{
Haemodynamic effects of pressure support and PEEP ventilation by nasal route in patients with stable chronic obstructive pulmonary disease
}

\author{
N Ambrosino, S Nava, A Torbicki, G Riccardi, C Fracchia, C Opasich, C Rampulla
}

\begin{abstract}
Background-Intermittent positive pressure ventilation applied through a nasal mask has been shown to be useful in the treatment of chronic respiratory insufficiency. Pressure support ventilation is an assisted mode of ventilation which is being increasingly used. Invasive ventilation with intermittent positive pressure, with or without positive end expiratory pressure (PEEP), has been found to affect venous return and cardiac output. This study evaluated the acute haemodynamic effects of short sessions of pressure support ventilation by nasal mask, with and without the application of PEEP, in patients with severe stable chronic obstructive pulmonary disease and hypercapnia.
\end{abstract}

Methods-Nine patients with severe stable chronic obstructive pulmonary disease performed sessions lasting 10 minutes each of pressure support ventilation by nasal mask while undergoing right heart catheterisation for clinical evaluation. In random order, four sessions of nasal pressure support ventilation were applied consisting of: (1) peak inspiratory pressure (PIP) $10 \mathrm{~cm} \mathrm{H}_{2} \mathrm{O}$, PEEP $0 \mathrm{~cm} \mathrm{H}_{2} \mathrm{O}$; (2) $P I P 10 \mathrm{~cm} \mathrm{H}_{2} \mathrm{O}$, PEEP $5 \mathrm{~cm} \mathrm{H}_{2} \mathrm{O}$; (3) PIP $20 \mathrm{~cm} \mathrm{H}_{2} \mathrm{O}$, PEEP $0 \mathrm{~cm} \mathrm{H}_{2} \mathrm{O}$; (4) $P I P 20 \mathrm{~cm} \mathrm{H}_{2} \mathrm{O}$, PEEP $5 \mathrm{~cm} \mathrm{H} \mathrm{H}_{2} \mathrm{O}$.

Clinica del Lavoro Foundation IRCCS, Center, Montescano, Pavia, Italy N Ambrosino $S$ Nava

G Riccardi

C Fracchia

C Opasich

C Rampulla

Department of Hypertension and Angiology, Medical Academy, Warzaw, Poland

A Torbicki

Reprint requests to: Dr N Ambrosino, Divisione di Pneumologia, Centro Medico di Riabilitazione 27040 Montescano, Pavia,

Italy

Received 16 July 1992 Returned to authors 14 September 1992 Revised version received 5 October 1992

Accepted 4 December 1992 and oxygen delivery was induced only by the addition of PEEP to both levels of PIP.

Conclusions-In patients with severe stable chronic obstructive pulmonary disease and hypercapnia, pressure support ventilation with the addition of PEEP delivered by nasal mask may have short term acute haemodynamic effects in reducing oxygen delivery in spite of adequate levels of $\mathrm{SaO}_{2}$.

(Thorax 1993;48:523-528)

Intermittent positive pressure ventilation (IPPV) applied through a nasal mask has been shown to be useful in the treatment of chronic respiratory failure. It is usually delivered by standard volume cycled ventilators in assisted or control modes. ${ }^{1}$ Continuous positive airway pressure (CPAP) administered by the nasal route has been suggested to facilitate respiratory muscle function during sleep in patients with severe chronic obstructive pulmonary disease (COPD). ${ }^{2}$ Pressure support ventilation (PSV) supplies a constant level of positive airway pressure during spontaneous inspiratory efforts, allowing the patient to maintain control of inspiratory and expiratory time and to interact with the set pressure to determine the ultimate flow and tidal volume delivered. ${ }^{3-5}$ PSV has been used in different clinical situations ${ }^{6-9}$ and is being increasingly applied in acute respiratory failure with a facial mask. ${ }^{10}$ In patients with severe stable COPD, pressure support ventilation by nasal mask (NPSV) improves diaphragmatic function and alveolar ventilation $^{11}{ }^{12}$; this effect may be enhanced by the application of external positive end expiratory pressure (PEEP). ${ }^{12}$

Mechanical ventilation may adversely affect haemodynamics. Invasive IPPV, with or without the application of PEEP, has been found to affect venous return and cardiac output. ${ }^{13-15}$ Other investigators have treated patients with chronic respiratory insufficiency with intermittent ventilation provided by negative pressure ventilators and different results on haemodynamics have been found with the iron lung, Cuirass or Ponchowrap ventilators. ${ }^{16-21}$

To our knowledge no information is available on the haemodynamic effects of noninvasive positive pressure ventilation apart from CPAP in patients with congestive heart failure. ${ }^{22}$ The aim of this study was therefore to test the acute haemodynamic effects of a short period of NPSV, with and without 
PEEP, in severe stable patients with COPD with hypercapnic respiratory insufficiency.

\section{Methods}

\section{SUBJECTS}

Studies were carried out on nine patients (eight men, age range 47-67 years), all of whom were smokers or ex-smokers with COPD (mean (SD) $\mathrm{FEV}_{1} / \mathrm{FVC}, 39 \%$ (6\%) and respiratory insufficiency $\left(\mathrm{PaO}_{2}, 49(7) \mathrm{mm}\right.$ $\mathrm{Hg} ; \mathrm{PaCO}_{2}, 56(7) \mathrm{mm} \mathrm{Hg}$ ) undergoing right cardiac catheterisation for clinical purposes. The demographic characteristics of the study population are shown in table 1 .

At the time of the study the patients had not suffered an exacerbation of respiratory symptoms for several months. No patient showed clinical signs of left ventricular disease or systemic arterial hypertension. One patient had undergone coronary artery bypass surgery 10 years earlier. All but one of the patients were receiving long term oxygen treatment; all but one was taking oral sustained theophylline, three patients were taking inhaled steroids and $\beta$ agonists, and one was receiving oral $\beta$ agonists. Two were taking digoxin, two nifedipine, and one transdermal release nitrate. No changes in medical or oxygen treatment were made during the two weeks preceding the study. All patients were familiarised with the technique of NPSV without PEEP for at least two weeks. All patients gave their informed consent for participation in the study which was approved by the ethical committee of Clinica del Lavoro Foundation.

\section{PULMONARY TESTS}

Dynamic lung volumes were evaluated with a water spirometer (Biomedin, Padova, Italy) in the seated posture, and static lung volumes were assessed by the helium dilution method. The predicted values used were those of Quanjer. ${ }^{23}$ An automated analyser (Radiometer ABL 500, Copenhagen, Denmark) was used to measure gas tensions in blood samples drawn from the radial artery.

\section{VENTILATORY TESTS}

After baseline tests, the patients were taught to perform NPSV administered by a bilevel airway pressure ventilator (BIPAP, Respironics, Monroeville, Pennsylvania,

Table 1 Mean (SD) demographic and physiological characteristics.

\begin{tabular}{lc}
\hline Sex (M:F) & $8: 1$ \\
Age (y) & $57(7)$ \\
Weight (kg) & $64(17)$ \\
Height (cm) & $162(5)$ \\
Body surface area (m²) & $1.66(0 \cdot 20)$ \\
Vital capacity (\% predicted) & $44(11)$ \\
FEV $/$ FVC (\%) & $39(6)$ \\
$\mathrm{Residual}^{2}$ volume (\% predicted) & $211(66)$ \\
$\mathrm{PaO}_{2}$ (mm Hg) & $49(7)$ \\
$\mathrm{PaCO}_{2}$ (mm Hg) & $56(7)$ \\
pH & $7.37(0.02)$ \\
\hline
\end{tabular}

FEV $_{1}$ - forced expiratory volume in one second; FVCforced vital capacity; $\mathrm{PaO}_{2}$-arterial oxygen tension; $\mathrm{PaCO}_{2}$-arterial carbon dioxide tension.
USA) while seated. BIPAP is a nasal CPAP blower modified with a solenoid system that allows timed cyclical delivery of positive airway pressure at two different levels, both in "spontaneous" (assisted) and controlled mode; the details have been extensively described elsewhere. ${ }^{1124}$ In the "spontaneous" mode inspiratory positive peak inflation pressure (PIP) up to a maximum of $22 \mathrm{~cm} \mathrm{H}_{2} \mathrm{O}$, and external PEEP can be set, but the patient triggers inspiration and expiration. In other words, pressure support ventilation can be delivered with the ability to add PEEP if required. NPSV was applied through a comfortable, tightly fitting nasal mask (Respironics, Monroeville, Pennsylvania USA).

On the two days preceding the haemodynamic studies patients underwent several learning sessions with different levels of PIP, with and without PEEP, by BIPAP in "spontaneous mode": (1) PIP set at $10 \mathrm{~cm} \mathrm{H}_{2} \mathrm{O}$ at the mask with no PEEP (nine patients); (2) PIP set at $10 \mathrm{~cm} \mathrm{H} \mathrm{H}_{2} \mathrm{O}$ with PEEP at $5 \mathrm{~cm}$ $\mathrm{H}_{2} \mathrm{O}$ at the mask (seven patients); (3) PIP set at $20 \mathrm{~cm} \mathrm{H}_{2} \mathrm{O}$ with no PEEP (nine patients); (4) PIP set at $20 \mathrm{~cm} \mathrm{H}_{2} \mathrm{O}$ with PEEP at $5 \mathrm{~cm}$ $\mathrm{H}_{2} \mathrm{O}$ (seven patients).

HAEMODYNAMIC STUDIES

On the third day patients underwent pulmonary artery catheterisation. After baseline measurements were made in the supine position, they again performed the four different sessions of NPSV, each of 10 minutes' duration. NPSV sessions were delivered randomly with no interval between each session. By the percutaneous approach of Seldinger, a $7 \mathrm{Fr}$ balloon tipped thermodilution pulmonary artery catheter (Edwards Laboratory, Santa Ana, California, USA) was positioned under fluoroscopy in one of the main pulmonary arteries. Filling pressures were measured in the standard manner and were zero referred to the level of the right atrium. The pulmonary artery pressure (PAP), right atrial pressure (RAP), pulmonary capillary wedge pressure (PWP), systemic blood pressure directly measured via a catheter inserted in the radial artery (Hewlett-Packard pressure conditioner HP $8805 \mathrm{D}$ and transducer HP $1290 \mathrm{~A}$ ), and the air pressure delivered at the mask (Honeywell transducer $\pm 300 \mathrm{~cm} \mathrm{H}_{2} \mathrm{O}$, Freeport, Illinois, USA) were continuously monitored and recorded on a polygraph (Gould ES 1000) together with the ECG. Radial artery pressure tracings were available in seven of nine patients because of the difficulty of inserting an arterial catheter in two patients. Cardiac output was estimated by the standard thermodilution technique with a cardiac output computer (Edwards 9520A, Edwards Laboratory, Santa Ana, California, USA) and the average of three measurements was recorded.

All haemodynamic and blood gas measurements were made at baseline and during the final minute of each NPSV session. Continuous monitoring of blood pressure, PAP, RAP, and ECG helped to ensure that, 
Table 2 Mean (SD) changes in blood gases during different sessions of nasal pressure support ventilation (NPSV)

\begin{tabular}{lllll}
\hline & $\begin{array}{l}\mathrm{PaO}_{2} \\
(\mathrm{~mm} \mathrm{Hg})\end{array}$ & $\begin{array}{l}\mathrm{SaO}_{2} \\
(\%)\end{array}$ & $\begin{array}{l}\mathrm{PaCO}_{2} \\
(\mathrm{~mm} \mathrm{Hg})\end{array}$ & $p H$ \\
\hline Baseline & $49(7)$ & $85(8)$ & $56(7)$ & $7 \cdot 37(0.02)$ \\
PIP 10 & $55(8)$ & $89(7)$ & $54(6)$ & $7 \cdot 37(0.03)$ \\
$\begin{array}{l}\text { PEEP 0 } \\
\text { PIP 10 }\end{array}$ & $53(8)$ & $89(8)$ & $55(9)$ & $7 \cdot 38(0.04)$ \\
$\begin{array}{l}\text { PEEP 5 } \\
\text { PIP 20 }\end{array}$ & $59(8)^{\star}$ & $91(5)^{\star}$ & $50(7)^{\star}$ & $7 \cdot 39(0.03)^{\star}$ \\
PEEP 0 & & & & \\
PIP 20 & $58(6)$ & $92(5)$ & $49(9)^{\star}$ & $7 \cdot 41(0.03)^{\star}$ \\
PEEP 5 & & & & \\
\hline
\end{tabular}

$\mathrm{PaO}_{2}$ - arterial oxygen tension; $\mathrm{SaO}_{2}$ - arterial oxygen saturation; $\mathrm{PaCO}_{2}$ - arterial carbon dioxide tension; PIP-peak inspiratory pressure; PEEP - positive end expiratory pressure.

${ }^{\star} \mathrm{p}<0.01$, each level of NPSV $v$ baseline

at the time measurements were made, a steady state had been reached. Haemodynamic monitoring continued after the ventilator was stopped until values returned to baseline which usually took about five minutes.

NPSV was performed using a fractional inspired oxygen $\left(\mathrm{FIO}_{2}\right)$ value of 0.21 except for two patients who performed the study (baseline and ventilation measurements) on oxygen at an $\mathrm{FIO}_{2}$ sufficient to maintain a $\mathrm{SaO}_{2}$ above $90 \%$.

The results are expressed as mean (SD) values. A $t$ test for paired data with Bonferroni's adjustment was used to compare each mode of NPSV with baseline and to test the effect of adding PEEP to both levels of PIP. Statistical significance was defined as $\mathrm{p}<0.01$.

\section{Results}

All patients tolerated both levels of PIP. Two patients did not tolerate the application of PEEP because of a sense of discomfort during exhalation.

\section{BLOOD GASES}

The results of blood gas analysis before and after 10 minutes of each session of NPSV are shown in table 2. During NPSV $\mathrm{PaO}_{2}$ increased significantly and $\mathrm{PaCO}_{2}$ decreased significantly at a PIP of $20 \mathrm{~cm} \mathrm{H}_{2} \mathrm{O}$. The addition of PEEP did not further improve blood gas tensions.

\section{HAEMODYNAMICS}

Figures 1 and 2 show a typical polygraphic recording of the different levels of ventilation. Haemodynamic parameters before and after 10 minutes of each session of ventilation are shown in table 3. All patients had moderate to severe pulmonary arterial hypertension. No significant change in heart rate, systolic blood pressure, PAP, RAP, and pulmonary vascular resistance was observed with all four levels of ventilation. Compared with baseline values, all levels of ventilatory support except PIP at $10 \mathrm{~cm} \mathrm{H}_{2} \mathrm{O}$ with no PEEP induced a significant increase in PWP. Only the application of PEEP to both levels of PIP induced small but significant reductions in cardiac output and in oxygen delivery $\left(\mathrm{Do}_{2}\right)$. Compared with measurements made under PIP alone, the addition of PEEP to both levels of PIP resulted in a reduction in cardiac output and $\mathrm{Do}_{2}$ in six out of seven patients. Reductions in cardiac output and $\mathrm{Do}_{2}$ in comparison with PIP alone did not reach statistical significance even when statistics included only these six patients. The one patient whose cardiac output and $\mathrm{DO}_{2}$ did increase with the addition of PEEP compared with PIP alone had undergone previous coronary artery bypass surgery. The observed changes did not induce any subjective complaint.

\section{Discussion}

Although the results of our study do not differ substantially from what would be expected with the standard use of PSV and PEEP, this
Figure 1 Polygraphic recordings in the basal state and during nasal pressure support ventilation with peak inspiratory pressure $(P I P)$ of $10 \mathrm{~cm}$ $\mathrm{H}_{2} \mathrm{O}$ without and with addition of positive end expiratory pressure (PEEP) of $5 \mathrm{~cm} \mathrm{H}_{2} \mathrm{O}$ in a representative patient. Chart speed $5 \mathrm{~mm} / \mathrm{s}$. BP-blood pressure; $P A P$ - pulmonary artery pressure; $P$ airwaypressure at the mask, $R A P$ - right atrial pressure.

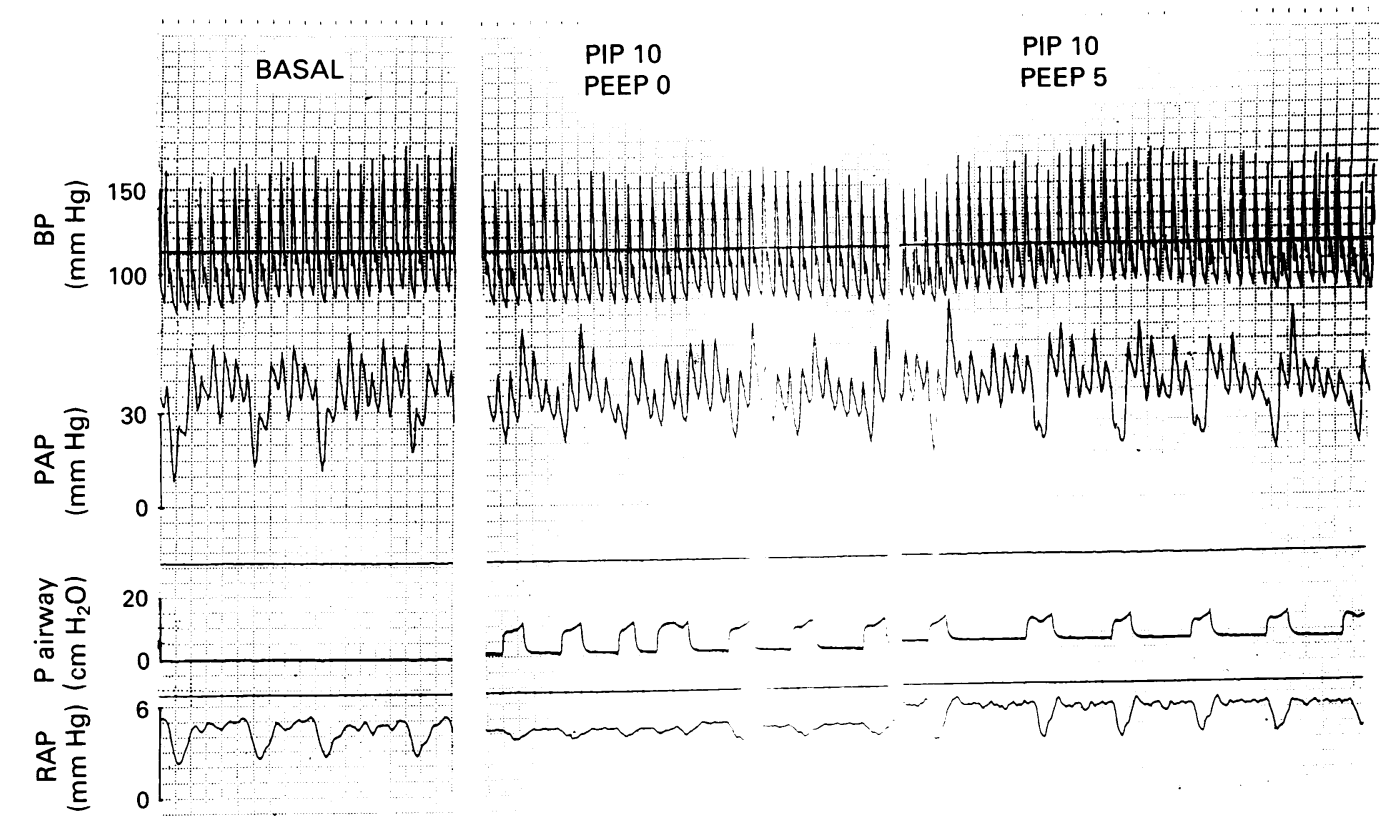


Figure 2 Polygraphic recordings in the basal state and during nasal pressure support ventilation with peak inspiratory $\mathrm{H}_{2} \mathrm{O}$ without and with addition of positive end $(\mathrm{PEEP})$ of $5 \mathrm{~cm} \mathrm{H}_{2} \mathrm{O}$ Chart speed $5 \mathrm{~mm} / \mathrm{s}$. $B P \_$blood pressure; $P A P$ - pulmonary artery pressure; $P$ airway pressure at the mask $R A P$ - right atrial pressure. pressure (PIP) of $20 \mathrm{~cm}$ expiratory pressure

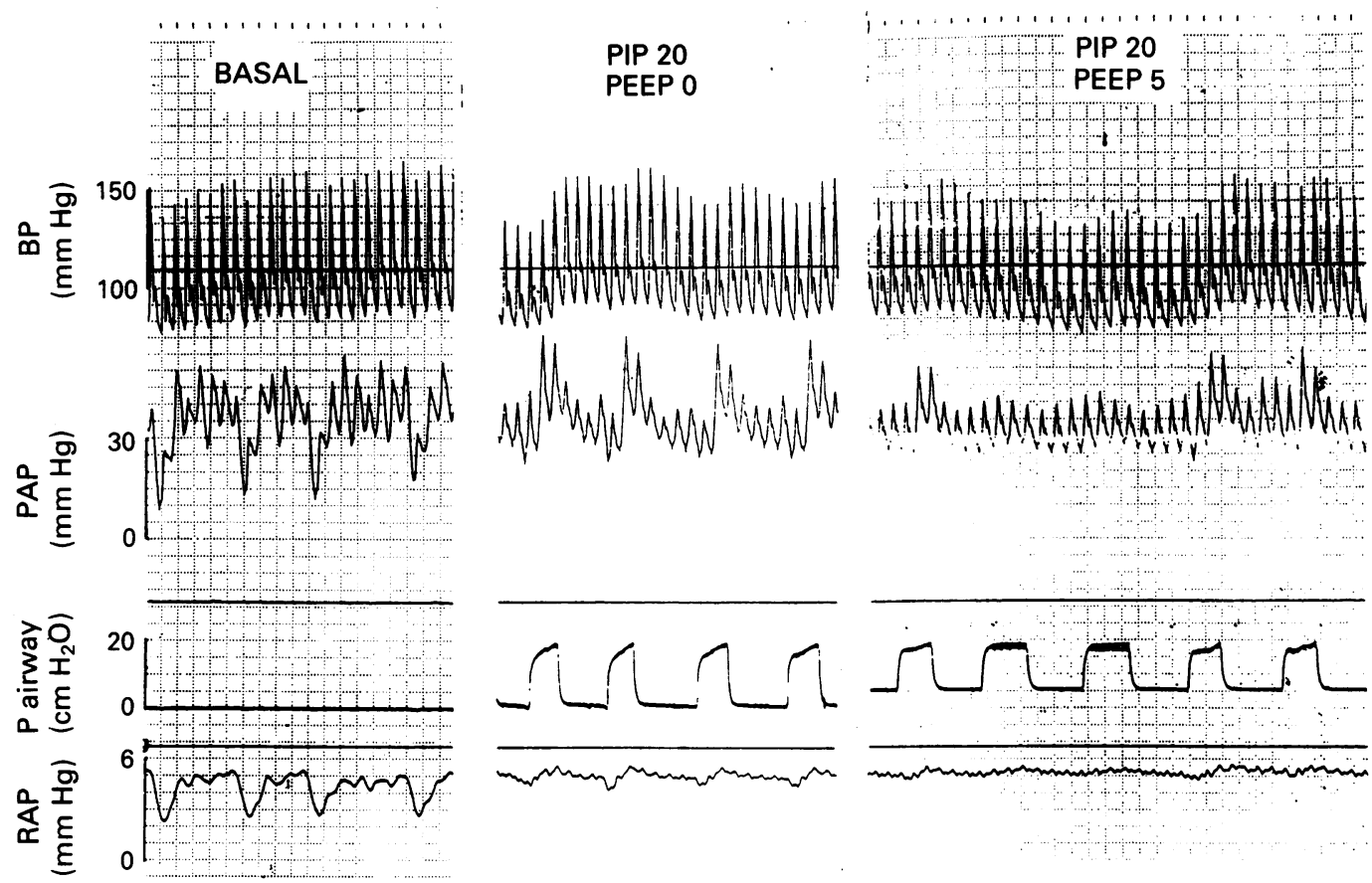

is the first study of the acute haemodynamic effects on these variables of non-invasive ventilation delivered to patients with COPD. As previously demonstrated, ${ }^{11} 12$ the short time (10 minutes) of application of NPSV with a PIP of $20 \mathrm{~cm} \mathrm{H}_{2} \mathrm{O}$ improved the arterial blood gas tensions, an effect not further increased by the addition of $5 \mathrm{~cm} \mathrm{H}_{2} \mathrm{O}$ of PEEP. Only when PEEP was added to both levels of PIP was a reduction in cardiac output observed compared with baseline levels. No improvement in $\mathrm{Do}_{2}$ was seen with any level of ventilation, and the application of PEEP resulted in a small but significant reduction in $\mathrm{DO}_{2}$ compared with baseline values.

Mechanical ventilation affecting transpulmonary gradients may greatly affect haemodynamics. In intubated patients, continuous positive pressure ventilation (CPPV) has been shown to depress cardiac output and systemic blood pressure to a degree related to the amplitude of applied PEEP. ${ }^{1314}$ This effect was attributed initially to the fall in venous return resulting from the rise in pleural pres-

Table 3 Mean (SD) changes in haemodynamics during different sessions of nasal pressure support ventilation (NPSV)

\begin{tabular}{|c|c|c|c|c|c|}
\hline & Baseline & $\begin{array}{l}\text { PIP } 10 \\
\text { PEEP } 0\end{array}$ & $\begin{array}{l}\text { PIP } 10 \\
\text { PEEP } 5\end{array}$ & $\begin{array}{l}\text { PIP } 20 \\
\text { PEEP } 0\end{array}$ & $\begin{array}{l}\text { PIP } 20 \\
\text { PEEP } 5\end{array}$ \\
\hline Heart rate (beats $/ \mathrm{min}$ ) & $78(10)$ & 79 (12) & $80(9)$ & $82(11)$ & $83(9)$ \\
\hline Systolic BP (mm Hg) & $131(16)$ & $135(14)$ & $137(14)$ & $134(16)$ & $126(18)$ \\
\hline Diastolic BP (mm Hg) & $78(22)$ & $75(11)$ & $76(12)$ & $76(11)$ & $74(14)$ \\
\hline Cardiac output ( $1 / \mathrm{min})$ & $5 \cdot 1(0.6)$ & $4.9(0.9)$ & $4.5(0.6)^{\star}$ & $4.7(0.9)$ & $4 \cdot 2(0 \cdot 8)^{\star}$ \\
\hline PAP (mm Hg) & $27(6)$ & $28(6)$ & $27(6)$ & $28(6)$ & $28(6)$ \\
\hline PWP (mm Hg) & $7(2)$ & $9(2)$ & $9(2)^{\star}$ & $11(2)^{\star}$ & $11(2)^{\star}$ \\
\hline $\mathrm{RAP}(\mathrm{mm} \mathrm{Hg})$ & $3(2)$ & $4(2)$ & $4(1)$ & $4(2)$ & $6(3)$ \\
\hline PVR (dynes $/ \mathrm{s} / \mathrm{cm}^{-5}$ ) & $298(70)$ & $306(79)$ & $309(83)$ & $301(106)$ & $336(129)$ \\
\hline $\mathrm{Do}_{2}\left(\mathrm{ml} / \mathrm{min} / \mathrm{m}^{2}\right)$ & $422(45)$ & $417(73)$ & $382(46)^{\star}$ & $408(79)$ & $367(70)^{\star}$ \\
\hline
\end{tabular}

BP_blood pressure; PAP_pulmonary artery pressure; PWP-pulmonary capillary wedge pressure; RAP-right atrial pressure; PVR-pulmonary vascular resistance; $\mathrm{DO}_{2}$-rate of oxygen delivery; PIP-peak inspiratory pressure; PEEP-positive end expiratory pressure.

${ }^{\star} \mathrm{p}<0.01$ each level of NPSV $v$ baseline. sure. This concept was challenged after the finding that right atrial transmural pressure was unchanged or was even elevated during ventilation with PEEP. ${ }^{25}$ Diastolic constriction of the ventricles by the inflated lungs occurs both during spontaneous and positive pressure ventilation. ${ }^{26-29}$ The right ventricle may therefore suffer from a relative increase in afterload due to the rise in pulmonary vascular resistance resulting from compression of intra-alveolar vessels, ${ }^{30}$ but these changes are considered small when compared with the haemodynamic effects of PEEP. Preload seems the main factor limiting cardiac output, especially in view of unchanged myocardial contractility. ${ }^{31}$ The fall in cardiac output and blood pressure is not usually followed either by reflex tachycardia or vasoconstriction, which is what was observed in our patients, suggesting that abnormal neurohormonal responses may contribute to the haemodynamic response to $\mathrm{CPPV} .{ }^{32}$

Haemodynamics during IPPV without PEEP have received less attention by previous investigators. The fall in pulmonary arterial flow with each inspiration may be attributed to the same preload limiting mechanisms as operate during CPPV. ${ }^{33}$ Nocturnal nasal CPAP has become the most important treatment for obstructive sleep apnoea and it has been used in selected patients with combined Cheyne-Stokes respiration and congestive heart failure. ${ }^{22}$ Leech $e t a b^{34}$ found no significant effects on heart rate, PAP, ventricular size, or cardiac index assessed non-invasively with increasing positive intrathoracic pressures and consequent lung hyperinflation in 19 normal volunteers and six patients with sleep apnoea. The data on the haemodynamic effects of PSV are few. Prakash and $\mathrm{Meij}^{7}$ observed that PSV with PIP levels comparable to those in our study $\left(20-22 \mathrm{~cm} \mathrm{H}_{2} \mathrm{O}\right)$ did not induce haemodynamic changes in intu- 
bated patients undergoing coronary artery bypass surgery. Our results in patients with stable COPD with hypercapnic respiratory insufficiency differ. As positive pressure acts as a ventricular assist device by reducing left ventricular afterload and direct ventricular compression, ${ }^{29}$ the deleterious effects of positive pressure upon venous return are minimal in patients with poor left ventricular function since they have flat atrial pressure-volume curves. The net effect is therefore unchanged or improved haemodynamics. Left ventricular function in our patients may be indirectly inferred to be satisfactory by their relatively normal levels of PWP and cardiac output. In patients with normal left ventricular function the ventricular assist will be relatively small, but the effect on atrial filling will predominate thereby explaining the fall in cardiac output. In our study NPSV, with and without PEEP, induced haemodynamic changes and, in the short term, reduced $\mathrm{DO}_{2}$ in spite of the ability of NPSV to improve levels of blood gases. In a previous study ${ }^{11}$ we observed that NPSV, at a PIP level of $20 \mathrm{~cm} \mathrm{H}_{2} \mathrm{O}$ without PEEP, was able to increase significantly alveolar ventilation and $\mathrm{PaO}_{2}$. As found in an earlier study in patients with COPD, ${ }^{35}$ a reduced abdominothoracic gradient across the diaphragm could explain the reduction in cardiac output with the application of NPSV. NPSV induced haemodynamic changes comparable to those observed in intubated patients undergoing CPPV. In fact, cardiac output decreased significantly and a significant increase in PWP was observed, PVR remaining unchanged. In our study, however, the maximal decrease in cardiac output observed was $30 \%$ (in a patient ventilated with $\mathrm{PIP}$ of $20 \mathrm{~cm} \mathrm{H} \mathrm{H}_{2} \mathrm{O}$ and PEEP of $5 \mathrm{~cm} \mathrm{H}_{2} \mathrm{O}$ ), and overall the reductions in cardiac output seemed not to have clinical relevance, although they induced a consequent reduction in $\mathrm{Do}_{2}$. Biondi et al ${ }^{36}$ found a non-significant $11 \%$ decrease in cardiac index at levels of PEEP above 10 cm $\mathrm{H}_{2} \mathrm{O}$.

We observed reductions in the respiratory oscillations of diastolic PAP with different levels of PIP and with the addition of PEEP (figs 1 and 2) which may be the result of a reduction in pleural pressure. ${ }^{37}$ This was found in a separate study in the same patients who, under NPSV, showed a progressive reduction in diaphragmatic electromyographic activity and in pleural (oesophageal) pressure with increasing levels of PIP. This reduction was enhanced by the addition of $5 \mathrm{~cm} \mathrm{H}_{2} \mathrm{O}$ of PEEP. ${ }^{12}$

This study has some limitations. Firstly, although the duration (10 minutes) of measurement of the haemodynamic effects of PIP/PEEP was short, a period of 10 minutes is considered sufficient to obtain stable and reproducible results, ${ }^{12238}$ and the four ventilatory modes were applied in succession and randomised to avoid any carry over effect. Furthermore, blood pressure, PAP, RAP, and ECG were recorded in real time during the study and at the moment of measurement these parameters were stable. An observation limited to 10 minutes of each mode of NPSV, however, may not be representative of a genuine therapeutic effect. This makes it difficult to draw conclusions about the addition of PEEP, as most patients with stable COPD would use NPSV for many hours overnight. All patients showed a rapid drop in $\mathrm{PaCO}_{2}$ on the institution of $20 \mathrm{~cm} \mathrm{H}_{2} \mathrm{O}$ of PIP which may play a part in the haemodynamic changes seen. With longer use of ventilation, however, homeostatic mechanisms are likely to come into play. ${ }^{39}$ These include salt and water retention due to activation of the renin angiotensin system as a consequence of the reduced cardiac output, or a reduction in atrial natriuretic factor as a direct effect of PEEP on right atrial size. These mechanisms tend to increase cardiac filling pressures and restore cardiac output. Once a new stable level is reached, cardiac output and $\mathrm{Do}_{2}$ may improve. The important clinical implication of this study, however, is that $\mathrm{FIO}_{2}$ should be increased initially to improve $\mathrm{Do}_{2}$, even if arterial blood gas tensions are adequate, in an attempt to offset the fall in cardiac output. Lastly, two of the nine patients who performed the study were receiving oxygen. Increasing the $\mathrm{FIO}_{2}$ would influence PVR; nevertheless, oxygen was administered during both basal measurements and ventilation in order to maintain a $\mathrm{SaO}_{2}$ above $90 \%$, so the relative changes in haemodynamic parameters should not have been greatly affected.

In conclusion, although the observed changes in haemodynamics had no effect on blood pressure and were not related to clinical signs, this study may suggest that the addition of PEEP to NPSV adds nothing to NPSV alone in improving oxygen delivery in stable patients with COPD.

1 Branthwaite $M$. Non-invasive and domiciliary ventilation: positive pressure techniques. Thorax 1991;46:208-12.

2 Petrof B, Kimoff RJ, Levy RD, Cosio M, Gottfried SB. Nasal continuous positive airway pressure facilitates respiratory muscle function during sleep in severe chronic obstructive pulmonary disease. Am Rev Respir Dis 1991;143:928-35.

3 MacIntire N, Nishima M, Usada Y, Tokiota H, Takezawa J, Shimada $Y$. The Nagoya conference on system design and patient-ventilator interactions during pressure support ventilation. Chest 1990;97:1463-6.

4 MacIntire NR. Respiratory function during pressure support ventilation. Chest 1986;89:677-83.

5 Brochard L, Pleskwa F, Lemaire F. Improved efficacy of spontaneous breathing with inspiratory pressure support. Am Rev Respir Dis 1987;136:411-5.

6 Brochard L, Harf A, Lorino H, Lemaire F. Inspiratory pressure support prevents diaphragmatic fatigue during weaning from mechanical ventilation. Am Rev Respir Dis 1989;139:513-21.

7 Prakash O, Meij S. Cardiopulmonary response to inspiratory pressure support during spontaneous ventilation vs conventional ventilation. Chest 1985;88:403-8.

8 Tokioka H, Saito S, Kosaka F. Pressure support ventilation as an alternative mode of assisted ventilation in patients with acute respiratory failure. Am Rev Respir Dis 1988;138:1169-79.

9 Braschi A, Iotti G. Partial ventilatory support in 1989. Int Care Med 1989;15:488-90.

10 Brochard L, Isabey D, Piquet J, Amaro P, Mancebo J, Messadi A, et al. Reversal of acute exacerbations of chronic obstructive lung disease by inspiratory assistance with a face mask. $N$ Engl $f$ Med 1990;323: 1523-30.

11 Ambrosino N, Nava S, Bertone P, Fracchia C, Rampulla C. Physiological evaluation of pressure support ventilation by nasal mask in patients with stable chronic obstructive pulmonary disease. Chest 1992;101:385-91.

12 Nava S, Ambrosino N, Rubini F, Fracchia C, Rampulla 
C, Torri G, et al. Effect of nasal pressure support ventilation and external PEEP on diaphragmatic activity in patients with severe stable COPD. Chest 1993;103: patients

13 Cournand A, Motley HL, Werko L, Richard DWJr. Physiological studies of the effects of intermittent positive pressure breathing on cardiac output in man. $A m \mathcal{F}$ Physiol 1948;23:944-53.

14 Sutter PM, Fairley HB, Isenberg MD. Optimum endexpiratory airway pressure in patients with acute pulmonary failure. N Engl f Med 1975;292:284-9.

15 Quist J, Pontoppidan H, Wilson RS. Hemodynamic responses to mechanical ventilation with PEEP. Anesthesiology 1975;42:45-55.

16 Beck GJ, Seanor HE, Barach AL, Gates D. Effects of pressure breathing on venous pressure: a comparative study of positive pressure applied to the upper respiratory passageway and negative pressure to the body of normal individuals. Am $\mathcal{F}$ Med Sci 1952;224:169-74.

17 Cook TI, Trimble C, Smith DE, Rehman I, Trummer MJ. Intermittent positive pressure and extrathoracic assisted breathing in hypovolemia. Arch Surg 1971;102: 586-8.

18 Skarbuskis M, Helal R, Zidulka A. Hemodynamic effects of external continuous negative pressure ventilation compared with those of continuous positive pressure ventilation in dogs with acute lung injury. Am Rev Respir Dis 1987;136:886-91.

19 Murray R, Criner G, Becker P, Mendoza J, Rubin L Negative pressure ventilation impairs cardiac function in patients with severe COPD (abstract). Am Rev Respir Dis 1989;139 (pt 2):A15.

20 Kinnear W, Petch M, Taylor G, Shneerson J. Assisted ventilation using cuirass respirators. Eur Respir $\mathcal{f}$ 1988;1:198-203.

21 Ambrosino N, Cobelli F, Torbicki A, Opasich C, Pozzoli $M$, Fracchia $\mathrm{C}$, et al. Hemodynamic effects of negativepressure ventilation in patients with COPD. Chest 1990;97:850-6

22 Bradley TD, Holloway RM, McLaughlin PR, Ross B, Walters J, Liu PP. Cardiac output response to continuous positive airway pressure in congestive heart failure. Am Rev Respir Dis 1992;145:377-82.

23 Quanjer PH. Working Party on "Standardization of lung function test". Bull Eur Physiopathol Respir 1983;19 (Suppl 5):7-10

24 Strumpf DA, Carlisle CC, William RP, Smith KW, Hil NS. An evaluation of the Respironics BIPAP bi-level CPAP device for delivery of assisted ventilation. Respir Care 1990;35:415-22.

25 Cassidy SS, Robertson CH, Pierce AK, Johnson RL Cardiovascular effects of positive end-expiratory pressure in dogs. $\mathcal{F}$ Appl Physiol 1978;44:743-50.
26 Cassidy SS, Ramanathan M. Dimensional analysis of the left ventricle during PEEP: relative septal and lateral wall displacements. Am $\mathcal{F}$ Physiol 1984;246:792-805.

27 Marini JJ, O'Quin R, Culver BH, Butler J. Estimation of transmural cardiac pressures during ventilation with PEEP. ₹ Appl Physiol 1982;53:384-91.

28 Robotham IL, Badke FR, Kindred MK, Beaton MK. Regional left ventricular performance during normal and obstructed spontaneous respiration. $\mathcal{f}$ Appl Physiol 1983;55:569-77.

29 Wallis TW, Robotham JL, Compean R, Kindred MK. Mechanical heart and lung interaction with positive end-expiratory pressure. $\mathcal{F}$ Appl Physiol 1983;54 1039-47.

30 Whittemberger JL, McGregor M, Berglund E, Borst HG Influence of the state of the lung on pulmonary vascular resistance. $f$ Appl Physiol 1960;15:878-82.

31 Robotham JL, Lixfield W, Holland L, MacGregor D, Bromberger-Barnea B, Permutt $S$, et al. The effects of positive end-expiratory pressure on right and left ventricular performance. Am Rev Respir Dis 1980;121: 677-83.

32 Cassidy SS, Schwiep F. Cardiovascular effects of positive end-expiratory pressure. In: Scharf SM, Cassidy SS, eds. Heart-lung interactions in health and disease. New York: Marcel Dekker, 1989:463-506.

33 Sharf SM, Brown R, Saunders N. Hemodynamic effects of positive pressure inflation. F Appl Physiol 1980;49: 124-31.

34 Leech JA, Ascah KJ. Hemodynamic effects of nasal CPAP examined by Doppler echocardiography. Chest 1991;99: 323-8.

35 Nava S, Ambrosino N, Zocchi L, Rampulla C. Diaphragmatic rest during negative pressure ventilation by pneumowrap. Assessment in normal and COPD patients. Chest 1990;98:857-65.

36 Biondi JW, Schulman DS, Soufer R, Matthay RA, Hines $\mathrm{RL}$, Kay HR, et al. The effect of incremental positive end-expiratory pressure on right ventricular hemodynamics and ejection fraction. Anesth Analg 1988;67: 144-51.

37 Grossoni M, Ukmar G, Rustici A, Morpurgo M. Can respiratory intrapleural pressure changes be calculated from pulmonary arterial pressure oscillations? In: Morpurgo M, Tramarin R, Rampulla C, Fracchia C, Cobelli F, eds. Pathophysiology and treatment of pulmonary circulation. New York: Springer Verlag, 1988: 129-38.

38 Pinsky MR, Desmet J, Vincent JL. Effect of positive endexpiratory pressure on right ventricular function in humans. Am Rev Respir Dis 1992;146:681-7.

39 Kharasch ED, Yeo K, Kenny MA, Buffington CW. Atrial natriuretic factor may mediate the renal effects of PEEP ventilation. Anesthesiology 1988;69:862-9. 